\title{
FAULT DETECTION OF ACTUATORS IN SUPERHEATERS TEMPERATURE CONTROL SYSTEMS
}

\author{
Matei Vinatoru, Eugen Iancu \\ Faculty of Automation, Computers and Electronics, University of Craiova, Romania \\ E-mail: vinatoru@automation.ucv.ro
}

\begin{abstract}
This paper has two immediate goals: Developing a simplified lumped parameters model that approximates the distributed parameters structure of steam superheaters; and developing a structure for fault detection and localization using actuators fault detection that can inform the operator about the faults following actuators blocking or changes in the burning process and heat transfer conditions. Copyright (C) 2005 IFAC
\end{abstract}

Keywords: fault detection and isolation, control design, modelling, identification.

\section{INTRODUCTION}

Steam superheater temperature control is critical to the efficient operation of steam turbines. Usually the control is realized with water that is sprayed into the steam stream after the steam has passed through the superheater blocks (assemblies). The steam temperature must be stable before steam is hitting the tips of turbine's blades [Viswanadham, 1987; Vinatoru, 2001]. The assembly of superheaters is a distributed parameter system and the control of the output temperature is difficult because there is a transfer time delay between the points where water is sprayed and the points where steam temperature is measured. Moreover, the gains, delays and time constants of the equivalent model of the superheaters also change significantly with the power load on the steam turbine due to changes in steam flow rates. It is necessary to introduce a new advanced predictive controller since the typical PID based control scheme requires complex gain scheduling and lead-lag feed forward compensation [Popovici, 1990].

The second problem in the superheater temperature control is the fault detection and isolation occurring in the control equipments (sensors and actuators) and control method implementation in fault conditions.
This paper describes the application of a new fault detection and isolation method based on the lumped parameter model of the steam superheaters that includes the transfer time delay of the steam and gas flows in the mass balance differential equations. A new closed loop control method achieves the actuator's fault isolation in fault conditions. The results demonstrate that this fault structure is easy to configure and it offers the solution to maintain the output temperature of the live steam constant using another spray water actuator.

\section{FAULT DETECTION AND ISOLATION STRUCTURE}

In the design of automatic control systems, a great emphasis is put on the structures capable to detect and isolate fault conditions. The existing solutions can be classified in two different categories [Chowdhury, 1998; Isermann 2004]:

a) Fault detection and identification using dedicated observers, detection and identification algorithms, and smart AHS simulation.

b) Fault management using FDIM architecture and simulation results. 


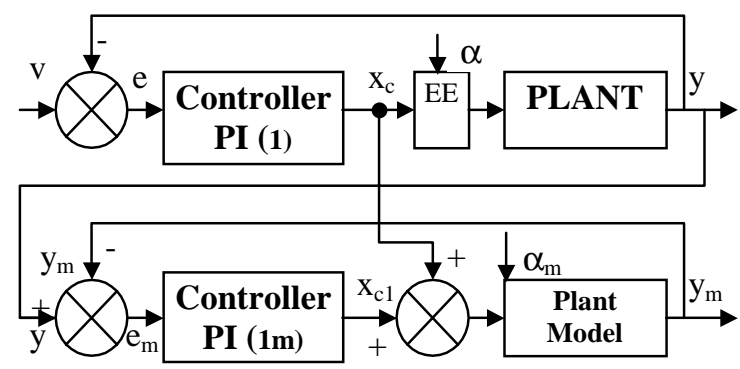

Fig.1. FDI Structure

For the later category, in figure 1 we present a structure for fault detection and isolation that assures fast detection of a fault described thru a parameter in the mathematical model.

Let consider the plant described by the following system

$$
\begin{gathered}
\dot{\bar{x}}=f\left(\bar{x}, x_{c}, \alpha\right) \\
y=C^{T} \cdot \bar{x}
\end{gathered}
$$

where $\bar{x}$ is the state vector, $\mathrm{y}$ is the measurable output of the plant, $\alpha$ is a parameter that describes a fault and $x_{c}$ is the control command.

The real controller (for PI type), is described by:

$$
\dot{x}_{c}=K_{R}(\dot{v}-\dot{y})+K_{I}(v-y)
$$

where $v$ is the set point of the control system.

The control structure for fault detection includes a plant model described by the following equations:

$$
\begin{gathered}
\dot{\bar{x}}_{m}=f\left(\bar{x}_{m}, x_{c}+x_{c 1}, \alpha_{m}\right) \\
y_{m}=C^{T} \cdot x_{m}
\end{gathered}
$$

And the control signal:

$$
\dot{x}_{c 1}=K_{R}\left(\dot{y}-\dot{y}_{m}\right)+K_{I}\left(y-y_{m}\right)
$$

Replacing variables $\dot{y}$ and $\dot{y}_{m}$ in (6) we get:

$$
\begin{aligned}
& \dot{x}_{c 1}=K_{R} C^{T} \cdot f\left(\bar{x}, x_{c}, \alpha\right)- \\
& -K_{R} C^{T} \cdot f\left(\bar{x}_{m}, x_{c}+x_{c 1}, \alpha_{m}\right)+K_{I} C^{T}\left(\bar{x}-\bar{x}_{m}\right)
\end{aligned}
$$

The FDI control structure, if designed properly with PI controller, will modify the control signal $\mathrm{x}_{\mathrm{c} 1}$ to obtain steady state error $e_{m s}=\lim _{t \rightarrow \infty} e_{m}(t)=0$. Therefore,

$$
\mathrm{y}_{\mathrm{s}}=\mathrm{y}_{\mathrm{ms}} \Rightarrow y-y_{m}=C^{T}\left(\bar{x}-\bar{x}_{m}\right) \rightarrow 0
$$

were $s$ denote steady state values.

In this case, considering the steady state regime we get from (1) and (4):

$$
\lim _{t \rightarrow \infty}\left[f\left(\bar{x}, \bar{x}_{c}, \alpha\right)-f\left(\bar{x}_{m}, \bar{x}_{c 1}, \alpha_{m}\right)\right]=0
$$

were $\alpha$ and $\alpha_{\mathrm{m}}$ are additive values of real and model actuators.
Through linearisation of equations (1) and (4) around steady state, the following linear system is obtained:

$$
\begin{aligned}
& \dot{\bar{x}}=A \cdot \bar{x}+b \cdot x_{c}+d \cdot \alpha \\
& \dot{\bar{x}}_{m}=A \cdot \bar{x}_{m}+b \cdot x_{c}+b \cdot x_{c i}+d \cdot \alpha_{m}
\end{aligned}
$$

In (10) it can be observed the difference between the mathematical description of the real plant and the mathematical plant model, described by the terms containing fault parameter $\alpha$. By substituting (10) in (7) we get:

$$
d\left(\alpha-\alpha_{m}\right)-b \cdot \bar{x}_{c s}=o
$$

and we can determine the faulty components very fast. In the single variable case:

$$
\alpha-\alpha_{m}=\frac{b}{d} \cdot x_{c 1}
$$

From the precedent analysis it results:

- the plant model shall reproduce as close as possible the real plant operation;

- the FDI control structure shall be asymptotically stable, which can be achieved by using a model controller identical with the plant controller;

- the response time of the FDI structure shall be smaller than the response time of the real plant;

- the perturbations that appear in the real process shall be included, as much as possible, in the model structure.

\section{DEVELOPMENT AND VALIDATION OF THE DYNAMIC SIMULATION MODEL}

The existing literature presents a series of models for the steam superheaters used in steam power plants [Flynn, 1999; Vinatoru 1994]. The goal of these models is to closely reproduce the real process but also to reduce the computational time for the process simulation, since these models are used for real time control and monitoring. We developed and verified a series of such models for the coal steam boilers used in the 330MW turbine-generator sets as follows:

- models using partial differential equations, since the superheaters are inherently distributed parameter systems and lumped parameters models, with the transfer delays generated by the steam and gas paths; - lumped parameters models having the transfer delays incorporated through supplementary differential equations.

The later model was considered as being the most adequate for the implementation of the fault detection and isolation structures.

\subsection{Lumped parameter model}

We consider as state variable an average value of the temperature along the heat exchanger. The simplified schematic diagram of steam superheaters of a steam boiler is presented in figure 2 . The heating coils SA1, 


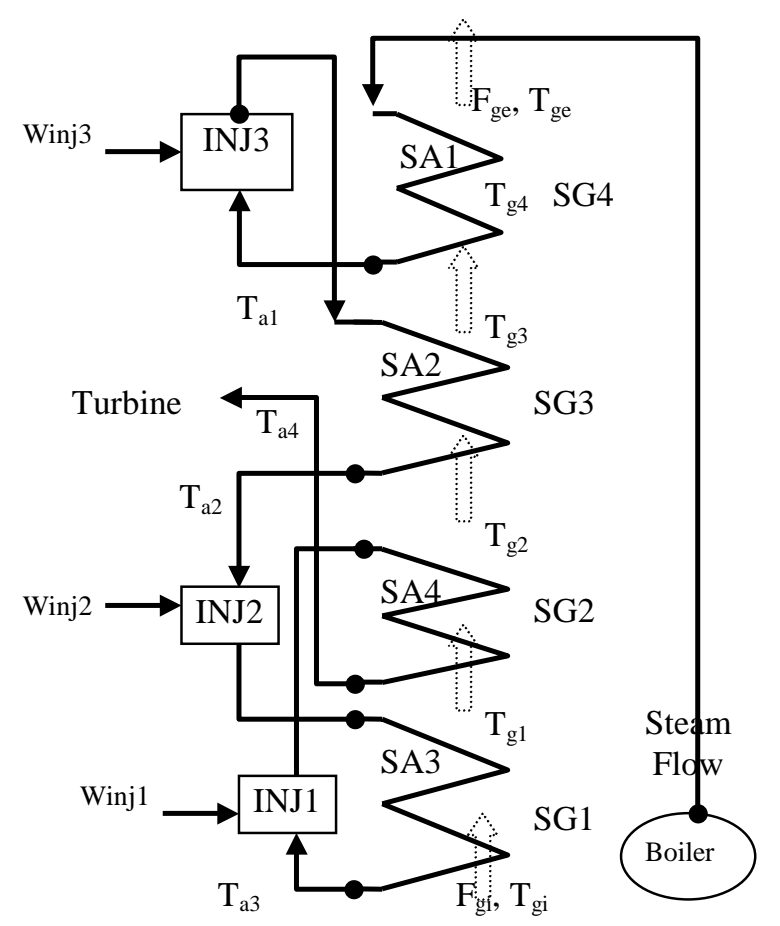

Gas Flow

Fig. 2. Simplified diagram of superheater

SA2, SA3, and SA4 and the corresponding gas path zones SG1, SG2, SG3, and SG4 are approximated by lumped parameter elements.

The following assumptions are considered:

- The model of steam superheat temperature control will be developed as a function of control inputs $\left(\mathrm{W}_{\mathrm{inj}, \mathrm{i}}\right)$ and external perturbations from turbine $\left(\mathrm{F}_{\mathrm{t}}\right)$ and vaporization area of the steam boiler $\left(\mathrm{T}_{\mathrm{ai}}, \mathrm{F}_{\mathrm{g}}\right)$.

- The steam flow at the input of the turbine, $F_{t}$, represents the main perturbation and it can be measured and all flows through superheaters are determined as functions of $F_{t}$.

- The hot gases temperature $T_{g i}$ and flow $F_{g}$ at the input of the superheat area, which hide non measurable perturbations, can provide some useful information regarding faults in the process of fuel burning and they must be evaluated by modelling.

In this conditions, the mathematical model is described by equations (13-29) where coefficients were computed using the steady state data for a 420 tones/hour steam boiler, working at $13.7 \mathrm{MPa}$ and $823 \mathrm{~K}$ and using coal and oil as fuel. Using the mass and heat transfer balance equations for each heat exchanger and injectors it results a set of equations corresponding to lumped parameter model of superheaters area.

a) First heat exchanger:

$$
\begin{aligned}
& T_{t a 1} \frac{d T_{a 1}}{d t}=\left(a_{a 1 i} T_{a 1 i}-a_{a 1} T_{a 1}\right) \cdot F_{a 1}+b_{a 1}\left(T_{g 4}-T_{a 1}\right) \\
& T_{t g 4} \frac{d T_{g 4}}{d t}=\left(a_{g 4 i} T_{g 4 i}-a_{g 3} T_{g 4}\right) \cdot F_{g}-b_{g 4}\left(T_{g 4}-T_{a 1}\right)
\end{aligned}
$$

b) Third injector

$$
\begin{aligned}
& T_{F a 1} \frac{d F_{a 1}}{d t}=-F_{a 1}+F_{a 2}-W_{i n j 1} \\
& T_{a 2 i}=T_{a 1}-1.97 * K_{l} . W_{i n j 1} ; T_{g 4 i}=T_{g 3}
\end{aligned}
$$

c) Second heat exchanger:

$$
\begin{aligned}
& T_{t a 2} \frac{d T_{a 2}}{d t}=\left(a_{a 2 i} T_{a 2 i}-a_{a 2} T_{a 2}\right) \cdot F_{a 2}+b_{a 2}\left(T_{g 3}-T_{a 2}\right) \\
& T_{t g 3} \frac{d T_{g 3}}{d t}=\left(a_{g 3 i} T_{g 3 i}-a_{g 3} T_{g 3}\right) \cdot F_{g 3}-b_{g 3}\left(T_{g 3}-T_{a 2}\right)
\end{aligned}
$$

d) Second injector

$$
\begin{aligned}
& T_{F a 2} \frac{d F_{a 2}}{d t}=-F_{a 2}+F_{a 3}-W_{i n j 2} \\
& T_{a 3 i}=T_{a 2}-1.97 * K_{2} \cdot W_{i n j 2} ; T_{g 3 i}=T_{g 2}
\end{aligned}
$$

e) Third heat exchanger:

$$
\begin{aligned}
& T_{t a 3} \frac{d T_{a 3}}{d t}=\left(a_{a 3 i} T_{a 3 i}-a_{a 3} T_{a 3}\right) \cdot F_{a 3}+b_{a 3}\left(T_{g 2}-T_{a 3}\right) \\
& T_{t g 1} \frac{d T_{g 1}}{d t}=\left(a_{g 1 i} T_{g 1 i}-a_{g 1} T_{g 1}\right) \cdot F_{g 1}-b_{g 1}\left(T_{g 1}-T_{a 3}\right)
\end{aligned}
$$

\section{f) First injector}

$$
\begin{aligned}
& T_{F a 3} \frac{d F_{a 3}}{d t}=-F_{a 3}+F_{a 4}-W_{i n j 1} \\
& T_{a 4 i}=T_{a 3}-1.97 * K_{1} . W_{i n j 1} ; T_{g I i}=T_{g i}
\end{aligned}
$$

g) Fourth heat exchanger:

\begin{tabular}{|c|c|c|c|c|}
\hline Block (k) & $\mathrm{T}_{\mathrm{ak}}(0)$ & $\mathrm{T}_{\text {taki }}$ & $\mathrm{a}_{\mathrm{aki}}$ & $a_{a k}$ \\
\hline SA1 & 669.7 & 65.19 & 0.025 & 0.0251 \\
\hline SA2 & 727.5 & 69.14 & 0.053 & 0.0535 \\
\hline SA3 & 763.3 & 177.91 & 0.046 & 0.0470 \\
\hline SA4 & 823.15 & 121.71 & 0.029 & 0.0292 \\
\hline SG1 & 1120.1 & 0.172 & 0.012 & 0.0111 \\
\hline SG2 & 1083.1 & 0.189 & 0.006 & 0.0047 \\
\hline SG3 & 1041.1 & 0.256 & 0.0076 & 0.0063 \\
\hline SG4 & 820.15 & 0.166 & 0.0034 & 0.0032 \\
\hline
\end{tabular}

$$
\begin{gathered}
T_{t a 4} \frac{d T_{a 4}}{d t}=\left(a_{a 4 i} T_{a 4 i}-a_{a 4} T_{a 4}\right) \cdot F_{a 4}+b_{a 4}\left(T_{g 2}-T_{a 4}\right) \\
T_{t g 2} \frac{d T_{g 2}}{d t}=\left(a_{g 2 i} T_{g 2 i}-a_{g 2} T_{g 2}\right) \cdot F_{g 2}-b_{g 2}\left(T_{g 2}-T_{a 4}\right)(26) \\
T_{F a 4} \frac{d F_{a 4}}{d t}=-F_{a 4}+F_{T} ; \\
T_{g 2 i}=T_{g 1} ; T_{a 1 i}=T_{a i}=618.15 \mathrm{~K} ; T_{g i}=1183.15 \mathrm{~K}
\end{gathered}
$$

were : $a_{a x}, a_{g x}, b_{a x}$ and $b_{g x}$ are constants and

$$
T_{t a x}=\frac{\rho_{a x} c_{a x} V_{a x}}{F_{T} c_{T}} ; \quad T_{t g x}=\frac{\rho_{g x} c_{g x} V_{g x}}{F_{g} \rho_{g i} c_{g i}} ; x=1,2,3 .
$$

The numerical values of these constants are presented in Table 1.

\section{Table 1. Equation parameters}




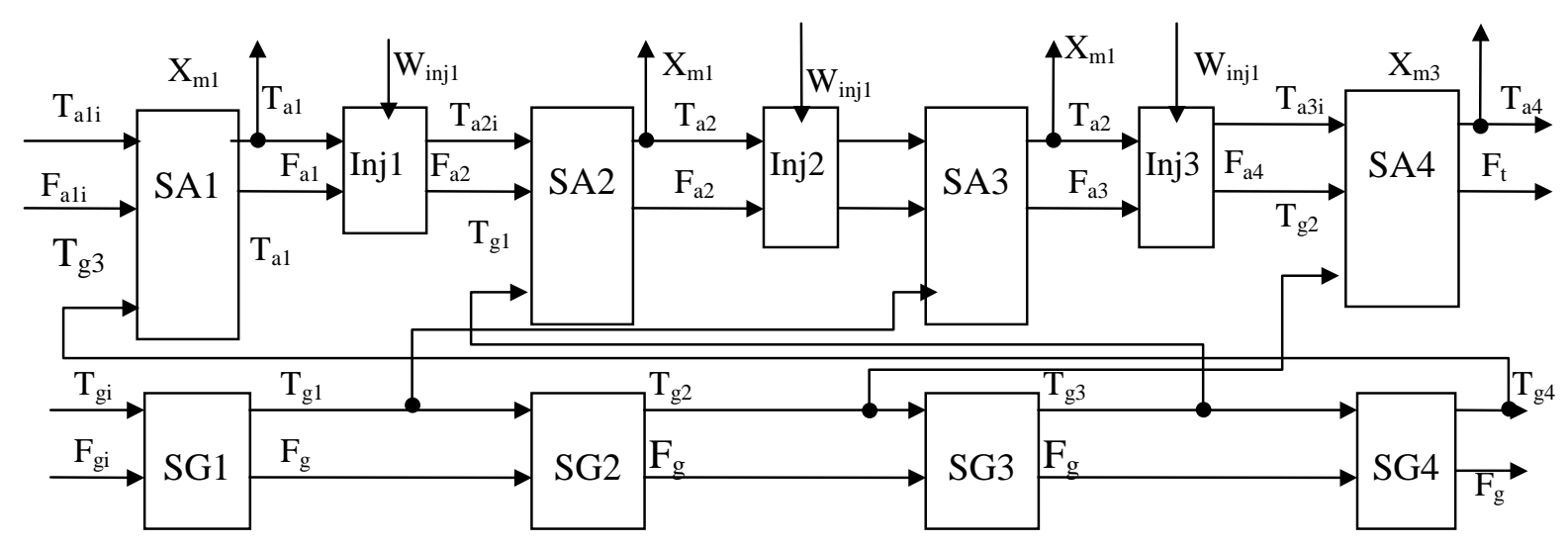

Fig. 4. Block diagram of superheater

Table 2. Spray parameters

\begin{tabular}{lll}
\multicolumn{2}{l}{ Table 2. Spray parameters } & \\
\hline \hline Flows & Fk $(0)$ & $\mathrm{T}_{\text {Faj }}$ \\
\hline Inj1 & 113.29 & 23.08 \\
Inj2 & 114.49 & 11.25 \\
Inj3 & 115.65 & 32.42 \\
Turbine & 118.01 & 35.03 \\
\hline
\end{tabular}

The transport delays for the steam exchanger tube transfer were simulated by mass transfer equations (15), (19), (23) and (27). In this case were neglected the transport delays for the gas flow.

The model validation and coefficients adjustment were done comparing computer simulation results and real experimental data for steam temperature curves. Equations (13-29) highlight the nonlinearities of the lumped parameter model. These nonlinearities are of type product between perturbation - state and perturbation - command. But this model does not highlight the transport delays that can play a major role, especially when the group works at variable load.

Using the equations (13 - 29) we can develop the block diagram presented in figure 4 . In figure 4, SA1, SA2, SA3, and SA4 are processes with big time constants (in the magnitude of tens of seconds), SG1, SG2, SG3, and SG4 on the hot gases path are processes with short time constants (under one second) and $X_{\mathrm{m} 1}$ to $\mathrm{X}_{\mathrm{m} 4}$ are the measurement points. This block diagram was used for the development of a Matlab - Simulink simulator of the steam superheaters. The simulation results have been validated by real experiments on the steam boiler. It is possible to develop a simplified linear model of the superheaters through linearisation of the equations (13-19) around the steady state point.

\section{APPLICATIONS OF STEAM SUPERHEATER MODELS}

The operating logs for some steam boilers from the power plants in the area have revealed a series of faults that can occur in the equipment or in the control structure:

- Blocking or hysteresis operation of actuators for spray flows $\mathrm{W}_{\text {inj1 } 1}, \mathrm{~W}_{\mathrm{inj} 2}$ and $\mathrm{W}_{\mathrm{inj} 3}$.

- Improper burning of fuel or improper pressure control in the burning zone that can lead to important changes in hot gases temperature $\mathrm{T}_{\mathrm{gi}}$ or flow $\mathrm{F}_{\mathrm{g}}$ and changes in the steam flow that enters the turbine.

-Changes of the heat transfer coefficients caused by build up inside or outside the superheaters' pipes and coils that can lead to changes in gas temperature at the input of superheaters.

\subsection{Sensitivity matrix}

Our goal is to detect the faults by measuring the accessible process variables in real time. For the given process, these variables are the steam temperatures at the exit from each superheater block. Since there is a strong interdependence between these variables and the possible defects that can occur in the control equipment, it is necessary to find an adequate method to choose the correct faultmeasurable outputs pairs.

For the conventional steam power plants, based on some experimental studies, the main faults that can appear in the superheaters are as follows:

- blocking of actuators (commands generated by the temperature controllers for the spray flows $\mathrm{W}_{\text {inj } 1}$, $\mathrm{W}_{\text {inj2 }}$, and $\mathrm{W}_{\mathrm{inj} 3}$ are not executed);

- improper burning of fuel that can change the hot gases temperature $\mathrm{T}_{\mathrm{gi}}$ and vaporization temperature $\mathrm{T}_{\mathrm{ai}}$;

In this case we can define the fault vector:

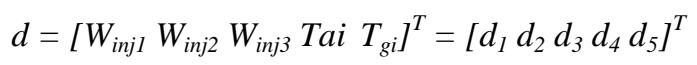

The vector of measurable variables is:

$$
\mathrm{X}_{\mathrm{t}}=\left[\begin{array}{llll}
\mathrm{T}_{\mathrm{a} 1} & \mathrm{~T}_{\mathrm{a} 2} & \mathrm{~T}_{\mathrm{a} 3} & \mathrm{~T}_{\mathrm{a} 4}
\end{array}\right]^{\mathrm{T}}
$$

representing the steam temperatures measured at the exit from each superheater (see fig. 2).

In order to choose the correct perturbation-output pairs, we define the sensitivity matrix (30): 


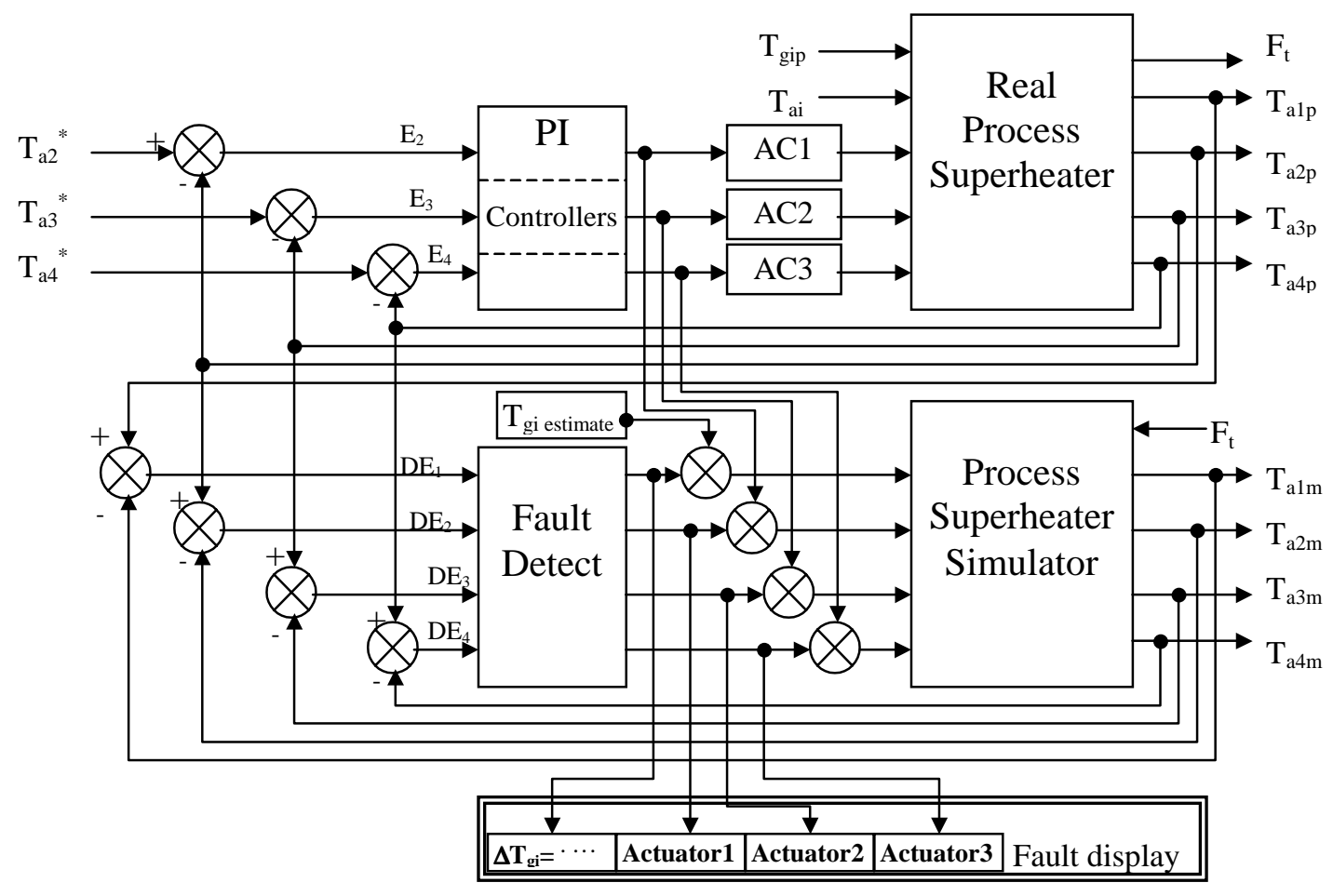

Fig.3. Fault detection block diagram

$M_{D}=\frac{\partial \bar{x}_{t}}{\partial \bar{d}}=\left[\frac{\partial \bar{x}_{t i}}{\partial \bar{d}_{j}}\right]=\left[\begin{array}{ccc}\frac{\partial T_{a 1}}{\partial d_{1}} & \cdots & \frac{\partial T_{a 1}}{\partial d_{5}} \\ \vdots & \cdots & \vdots \\ \frac{\partial T_{a 4}}{\partial d_{1}} & \cdots & \frac{\partial T_{a 4}}{\partial d_{5}}\end{array}\right]$ (30)

which allows us to choose the correct fault-output pairs using the channels that have the highest sensitivity. From equations (13-29) results the form for matrix $\mathrm{M}_{\mathrm{D}}$ presented in (30), where: $m_{11}=a_{\mathrm{a} 1} T_{\mathrm{a} 1}$ $a_{\mathrm{a} 1 \mathrm{i}} T_{\mathrm{a} 1 \mathrm{i}} ; m_{15}=a_{\mathrm{a} 1 \mathrm{i}}\left[F_{\mathrm{t}}-\Sigma W_{\mathrm{inj} 1}\right] ; m_{21}=a_{\mathrm{a} 2} T_{\mathrm{a} 2}-a_{\mathrm{a} 2 \mathrm{i}}\left[T_{\mathrm{a} 1 \mathrm{i}}-\right.$ $\left.1.973 K_{3} \quad W_{\text {inj } 3}\right] ; m_{23}=-a_{\mathrm{a} 2 \mathrm{i}} 1.973 \quad \mathrm{~K}_{3}\left[F_{\mathrm{t}}-W_{\mathrm{inj} 1}-W_{\mathrm{inj} 2}\right] ;$ $m_{31}=a_{\mathrm{a} 3} T_{\mathrm{a} 3}-a_{\mathrm{a3i}}\left[T_{\mathrm{a} 2 \mathrm{i}}-1.973 K_{2} \quad W_{\mathrm{inj} 2}\right] ; \quad m_{32}=-a_{\mathrm{a} 3 \mathrm{i}} 1.973$ $\mathrm{K}_{2}\left[F_{\mathrm{t}}-W_{\mathrm{inj}}\right] ; m_{41}=-a_{\mathrm{a4i}} 1.973 \mathrm{~K}_{1} F_{\mathrm{t}}$.

$$
M_{D}=\left[\begin{array}{ccccc}
m_{11} & m_{11} & m_{11} & 0 & m_{15} \\
m_{21} & m_{21} & m_{23} & 0 & 0 \\
m_{31} & m_{32} & 0 & 0 & 0 \\
m_{41} & 0 & 0 & 0 & 0
\end{array}\right]
$$

Using for equations (13-29) the coefficients presented in table 1 , the numerical form of sensitivity matrix is:

$$
M_{D}=\left[\begin{array}{ccccc}
1.345 & 1.345 & 1.345 & 0 & 2.79 \\
3.35 & 3.35 & -11.94 & 0 & 0 \\
2.09 & -10.624 & 0 & 0 & 0 \\
-6.739 & 0 & 0 & 0 & 0
\end{array}\right]
$$

\subsection{The structure for fault detection and isolation.}

These results will allow us to implement the fault detection and isolation structure presented in figure 3 , as per the elements presented in cap. 2 .
We can define the pairs that represent the direct channels fault-perturbed output: (Winj1-Ta2, Winj2Ta3) and remaining available the pair (Winj3-Ta4) although Ta4 can also modify simultaneously $\mathrm{Ta} 2$ and Ta3. The perturbations in vaporization system (Tai and Fai) can also modify Ta1. Accordingly we can define the error vector $D E$ as a matrix function of fault vector .

$$
D E=\left[\begin{array}{l}
T_{a 1 p}-T_{a 1 m} \\
T_{a 2 p}-T_{a 2 m} \\
T_{a 3 p}-T_{a 3 m} \\
T_{a 4 p}-T_{a 4 m}
\end{array}\right]=F\left(\left[\begin{array}{l}
T_{g i n} \\
W_{i n j 1} \\
W_{i n j 2} \\
W_{i n j 3}
\end{array}\right]\right)
$$

\subsection{Simulation results}

Using the simulation diagram presented in figure 3 we obtained the following experimental results:

a. For normal operation of the actuators or of the burning and vaporization process, the fault display indicates zero value for the whole transition time of the control loops, generated by set-point changes for the PI temperature controllers or change of steam flow entering the turbine. Simulation results are presented in figure 4.

b. If the actuators' transfer coefficients are changing from the normal value 1 to a fault value $\mathrm{x}$, the outputs $y 1$ and/or $y 2$ of the fault synthesis block are changing and tend to stabilize at the value 1-x indicating the fault difference. Results are presented in figures 5 and 6. 


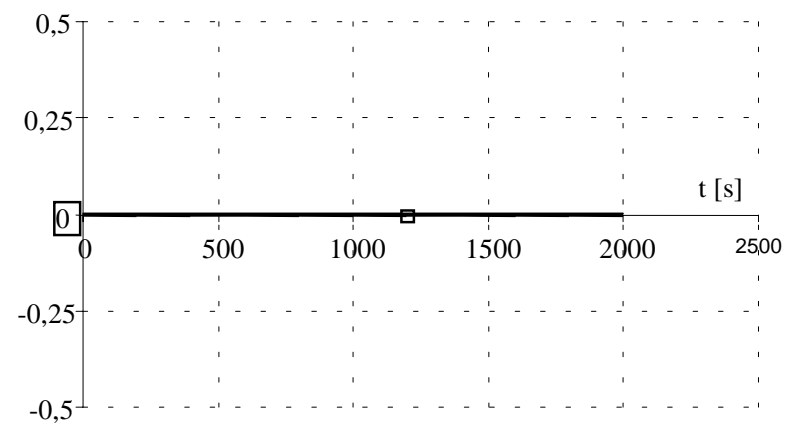

Fig. 4. Display diagram at set-point change

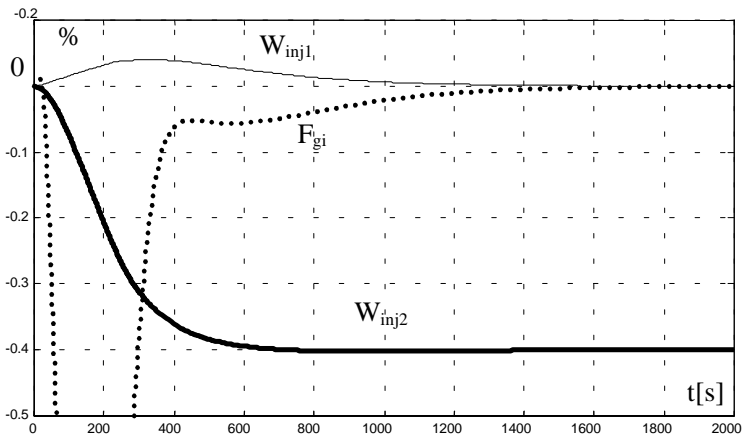

Fig. 5. Display diagram at AC2 fault

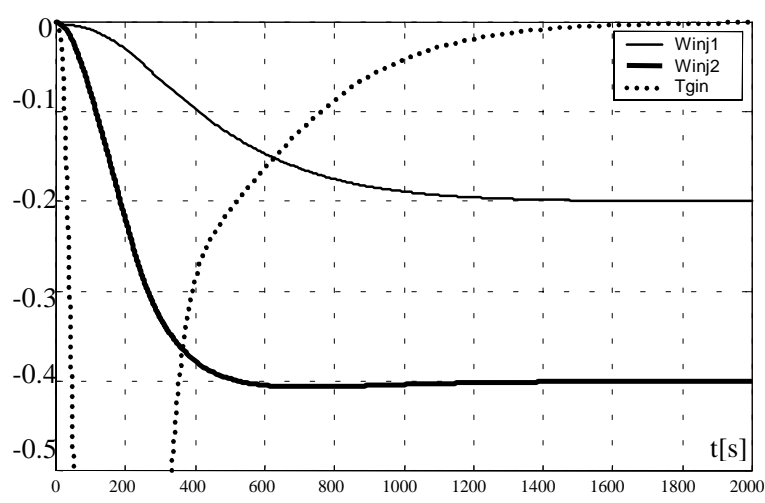

Fig. 6. Display diagram at $\mathrm{AC} 1$ and $\mathrm{AC} 2$ faults

\section{CONCLUSIONS}

For the improvement of reliability, safety and efficiency, advanced methods of control, monitoring, fault detection and diagnosis became increasingly important for the technical processes from the power plant. The safe operation of equipment avoids the damage of the power systems and accidental stops and increases the economic efficiency of the technological operations. Therefore it is necessary to improve the methods for early detection of process and equipment faults. This paper reports some results on an alternative approach to fault detection and isolations.

The fault detection and isolation structure for steam superheaters is the result of the authors' research work for the modernization of the power groups in the power plants from Oltenia region (Romania).
This structure allows the operators of the power plants to detect on-line the faults that can appear inside the equipment and processes that take place in steam boilers and superheater system. Similar structures were developed also for other blocks of the power groups and can be easily implemented on the group supervising computers that collect information about the group. This structure does not require supplementary equipment; it can be implemented on the existing monitoring digital control system of the power plants.

\section{REFERENCES}

Chowdhury, F.N., Aravena J.L., (1998), A Modular Methodology for Fast Fault Detection and Classification in Power Systems, IEEE Trans. Control and System Technology, Vol. 6, No. 5, pp. 623-632.

Dimirovski, G.M., W.Y. Jing, J.S. Zhang (1998). On decentralized output feedback control of a class of composite systems with delay interconnections and uncertainties, International Conference on CONTROL '98, Swansea UK

Domeracki, W., et al., (1997), Topping Combustor Application to the Wilsonville Advanced Power System Development Facility, Proceedings of the $14^{\text {th }}$ International Conference on Fluidised Bed Combustion, Vancouver, Canada.

Flynn M.E., O’Mallei M.J., (1999), Drum System Dinamic Simulation, IEEE Tran. on Power Systems, Vol.14, No.1, pp. 209-217.

Frank, P.M., (1990), Fault Diagnosis in dynamic systems using analytical and knowledge-based redundancy - a survey and some new results, Automatica, Vol.26, No.3, pp. 459-474.

Isermann, R.,( 1997) Supervision, fault detection and fault diagnosis methods- An introduction, Control Engineering Practice, 5(5), , 639 - 652.

Isserman, R., (2004), Model-Based Fault Detection and Diagnosis - Status and Application- , $16^{\text {th }}$ IFAC Symposium on Automatic Control ACA2004, Petersburg, Russia.

Popovici D., Bhakkar V.P., (1990) Distributed Computer Control for Industrial Automation, Marcel Dekker Inc., New York.

Tan W., H.J. Marquez, T. Chen, (2002), Multivariable Robust Controller Design for a Boiler System, IEEE Trans. on Control Systems Technology, Vol.10, No.5, pp. 735-742.

Vinatoru, M., (1994). Control System Study for steam superheaters, SINTES 7, vol. 1, Craiova

Vinatoru, M., (2001), Industrial Process Control, Ed. Universitaria, Craiova

Viswanadham, N., J. H. Taylor, E. C. Luce, (1987,), A Frequency-Domain Approach to Failure Detection and Isolation with Application to GE21 Turbine Engine Control Systems, Control Theory and Advanced Technology, 3(1), p.603 614. 